\title{
Depsipeptide nucleic acids: prebiotic formation, oligomerization, and self-assembly of a new candidate proto-nucleic acid
}

David M. Fialho, ${ }^{1}$ Suneesh C. Karunakaran, ${ }^{1}$ Katherine W. Greeson, ${ }^{1}$ Isaac Martínez, ${ }^{1}$ Gary B. Schuster, ${ }^{1}$ Ramanarayanan Krishnamurthy, ${ }^{2,3}$ and Nicholas V. Hud ${ }^{1,2, *}$

${ }^{1}$ School of Chemistry and Biochemistry and Parker H. Petit Institute for Bioengineering and Bioscience, Georgia Institute of Technology, Atlanta, Georgia 30332, USA. ${ }^{2}$ NSF-NASA Center for Chemical Evolution, Atlanta, Georgia 30332, USA. ${ }^{3}$ Department of Chemistry, The Scripps Research Institute, La Jolla, California 92037, USA.

\begin{abstract}
The mechanism by which genetic polymers spontaneously formed on the early Earth is currently unknown. The RNA World hypothesis implies that RNA oligomers were produced prebiotically, but the demonstration of this process has proven challenging. Alternatively, RNA may be the product of evolution and some, or all, of its chemical components may have been preceded by functionally analogous moieties that were more readily accessible under plausible early-Earth conditions. We report a new class of nucleic acid analog, depsipeptide nucleic acid, which displays several properties that make it an attractive candidate for the first informational polymer to arise on the Earth. The monomers of depsipeptide nucleic acids can form under plausibly prebiotic conditions. These monomers oligomerize spontaneously when dried from aqueous solutions to form nucleobase-functionalized depsipeptides. Once formed, these depsipeptide nucleic acid oligomers are capable of complementary self-assembly, and are resistant to hydrolysis in the
\end{abstract}


assembled state. These results suggest that the initial formation of primitive, selfassembling, informational polymers may have been relatively facile.

\section{Introduction}

The prebiotic emergence of the first genetic polymers is a poorly understood phenomenon. ${ }^{1}$ The influential RNA World hypothesis suggests that pre-formed nucleosides or nucleotides, through some hitherto unclear mechanism, spontaneously polymerized to form RNA polymers. ${ }^{2}$ However, despite repeated attempts, demonstrating the formation of oligomeric RNA from mononucleotides in a plausibly prebiotic manner is still a formidable challenge. ${ }^{3-4}$ This, and other issues associated with the initial formation of the nucleosides, suggest that RNA is a product of evolution, and was preceded by a proto-RNA polymer that was similar in function but more easily accessed in a prebiotic manner..$^{5-9}$

A number of proto-RNA nucleobases have been suggested that have greater propensities for self-assembly ${ }^{10-13}$ and are more reactive with ribose $\mathrm{i}^{10,12,14-17}$ and other sugars $^{13,} 18$ than adenine, guanine, uracil, or cytosine (the canonical RNA nucleobases). Similarly, it may be that chemical features and properties of the backbone of proto-RNA differed significantly from RNA. The backbone of RNA consists of two principal components: the ribose sugar and the phosphate linker. A number of studies have been performed on the formation and base-pairing properties of phosphodiester-linked nucleic acids with alternative sugars. ${ }^{19-20}$ The prebiotic feasibility of the phosphodiester linkage has long been disputed, ${ }^{21}$ although some recent studies offer solutions to some obstacles to prebiotic phosphorylation. ${ }^{22-24}$ A number of alternatives to the phosphodiester linkage have been suggested, including acetals, ${ }^{25}$ amides, ${ }^{26-27}$ phosphite esters, ${ }^{28}$ and thiophosphate esters. ${ }^{29}$ 
The carboxylic ester linkage, which arguably has more in common with the phosphodiester linkage than most other proposed alternatives, has been investigated for nucleic acid analogs, but has only been formed under non-prebiotic conditions with a carbodiimide condensing agent. ${ }^{30-31}$

In the context of proto-polypeptide formation, it has been found that oligoesters are formed readily from $\alpha$-hydroxy acids under relatively mild drying conditions and without the use of a condensing agent. ${ }^{32}$ Furthermore, when $\alpha$-hydroxy acids and $\alpha$-amino acids are combined in wet-dry cycling reactions, depsipeptide oligomers (containing both ester and amide moieties) are readily formed. ${ }^{33-34}$ It may be that proto-nucleic acids were also formed with ester and/or amide linkages, which were, through a process of chemical and/or biological evolution, eventually replaced by the more optimal, but prebiotically less accessible, phosphodiester linkage. ${ }^{6-8}$

In this study, we describe a new class of plausibly prebiotic polymer, depsipeptide nucleic acid, based on nucleobase-functionalized $\alpha$-hydroxy acid- $\alpha$-amino acid heterodimers as the proto-nucleic acid monomers. These monomers can be formed under plausibly prebiotic conditions and oligomerize by esterification, without the use of a chemical condensing agent, to form depsipeptide nucleic acids. Furthermore, depsipeptide nucleic acid oligomers self-assemble and show backbone-dependent resistance to hydrolysis. This new class of oligomers has the potential to function as an informational base-pairing system, and the specific compounds used in this study serve as models for prebiotic polymer systems that may be ancestral to more advanced genetic systems.

\section{Prebiotic Synthesis of Depsipeptide Nucleic Acid Monomers}


The prebiotic synthesis of nucleobase-functionalized compounds capable of oligomerization is described in the literature and has been discussed in a prebiotic context by Cleaves: nucleophilic nucleobases react readily with acrolein (a plausibly prebiotic compound ${ }^{35}$ ) to give, among other products, $\gamma$-nucleobase-functionalized aliphatic aldehydes. ${ }^{36}$ These aldehydes can act as substrates for cyanohydrin or $\alpha$-amino nitrile formation, which are hydrolyzed to give $\gamma$-nucleobase- $\alpha$-hydroxy acids or $\gamma$-nucleobase- $\alpha$ amino acids respectively. ${ }^{7}$ This synthetic path was also proposed by Miller for the formation of $\gamma$-functionalized amino acids such as methionine. ${ }^{37}$ A prebiotic precedent for the formation of $\gamma$-nucleobase-functionalized aldehydes was also recently demonstrated by Rodriguez et al., who found that performing Miller-Urey-type electrolysis reactions in a reducing atmosphere above aqueous solutions containing nucleobases produced, as the major products, 1,4-addition products of nucleobases (canonical or noncanonical) with Michael acceptors, including acrolein. ${ }^{38}$

Accordingly, we attempted one-pot, aqueous syntheses of $\gamma$-nucleobasefunctionalized cyanohydrins from the reactions of one canonical and two noncanonical plausibly prebiotic heterocycles, cyanuric acid (Cy), melamine (Mel), and adenine (Ad), with acrolein and with potassium ferrocyanide as the cyanide source. These bases were chosen because they are formed in the same model prebiotic reaction, ${ }^{39}$ and because cyanuric acid, with an acceptor-donor-acceptor hydrogen-bonding pattern, can form aqueous hexad-based supramolecular assemblies by Watson-Crick-like pairing with derivatives of melamine (donor-acceptor-donor), ${ }^{11}$ as well as supramolecular polymers with homo-adenine (donoracceptor) RNA or PNA oligomers. ${ }^{40-42}$ Ferrocyanide was chosen as the cyanide source because iron(II) cyanide complexes have been noted as compounds that were likely present 
on the early Earth (due to the inferred abundance of iron(II) and cyanide, ${ }^{43}$ or due to their direct detection in meteorites ${ }^{44}$ ) which can act as a slowly-releasing cyanide reservoir. In this regard, ferrocyanide has been successfully used in aqueous Strecker reactions as a "green" alternative to methods that employ more toxic cyanide sources. ${ }^{45}$

The aqueous reactions of cyanuric acid and adenine with acrolein and potassium ferrocyanide produced the corresponding nucleobase-functionalized cyanohydrins (Supplementary Figs 5 and 7), and acidic hydrolysis of these crude reaction mixtures gave a cyanuric acid-functionalized hydroxy acid, CyHA (Fig. 1a, Supplementary Fig. 6), and an adenine-functionalized hydroxy acid, $\operatorname{Ad}^{\mathrm{HA}}$ (Fig. 1b, Supplementary Fig. 8), respectively. Melamine, when combined with potassium ferrocyanide, precipitates to form an insoluble salt; therefore, only a small amount of a melamine-acrolein adduct is formed (Supplementary Fig. 9). However, when acetone cyanohydrin is used as a cyanide source, melamine remains soluble, and a large amount of melamine-acrolein adduct is formed, but only a small amount of melamine-functionalized cyanohydrin is formed (Supplementary Fig. 11), which is likely due to sequestration of the aldehyde substrate by cyclization of the melamine-acrolein adduct (Supplementary Fig. 14). 

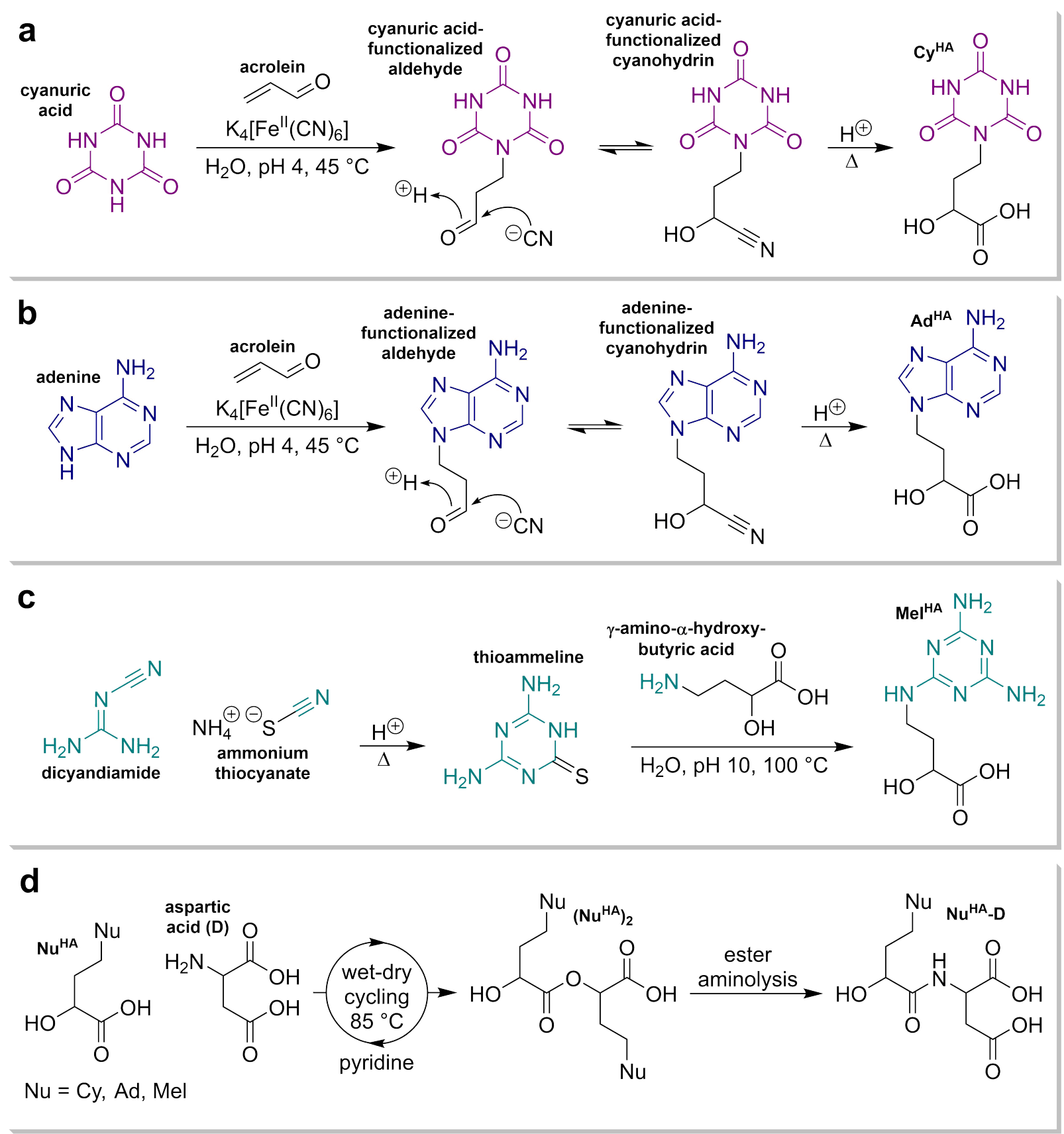

Figure 1 | Prebiotic syntheses of $\gamma$-nucleobase-functionalized $\alpha$-hydroxy acids and nucleobase-functionalized $\alpha$ -

hydroxy acid- $\boldsymbol{\alpha}$-amino acid heterodimers. a, The reaction of cyanuric acid with acrolein in the presence of potassium ferrocyanide gives the $\gamma$-cyanuric acid-functionalized aldehyde, which reacts with cyanide to form the corresponding cyanohydrin. Upon acidic hydrolysis, $\mathrm{Cy}^{\mathrm{HA}}$ is formed. $\mathbf{b}$, The reaction of adenine with acrolein in the presence of potassium ferrocyanide gives the $\gamma$-adenine-functionalized aldehyde, which reacts with cyanide to form the corresponding cyanohydrin. Upon acidic hydrolysis, $\mathrm{Ad}{ }^{\mathrm{HA}}$ is formed. c, The reaction of dicyandiamide with thiocyanate gives thioammeline, 
which reacts further with $\alpha$-hydroxy- $\gamma$-aminobutyric acid by nucleophilic aromatic substitution to form MelHA. d, When subjected to wet-dry cycles at $85^{\circ} \mathrm{C}$ from an aqueous solution containing pyridine, nucleobase-functionalized hydroxy acids condense with aspartic acid (via an ester homodimer intermediate) to form nucleobase-functionalized heterodimers.

Although a melamine-functionalized cyanohydrin was not formed in large amounts, the prebiotic formation of aminoalkyl nucleobases can also occur through nucleophilic aromatic substitution of sulfur-substituted heterocycles. ${ }^{17,} 46$ Thioammeline, which readily forms from the reaction of dicyandiamide (the dimer of cyanamide) with thiocyanate, ${ }^{47}$ reacts with amines to form melamine derivatives. ${ }^{48}$ The reaction of thioammeline with $\alpha$ hydroxy- $\gamma$-aminobutyric acid (itself formed prebiotically from acrolein by the Cleaves-Miller path to $\gamma$-functionalized amino acids and hydroxy acids ${ }^{37}$ ) gives the melamine-functionalized hydroxy acid, Mel ${ }^{\mathrm{HA}}$ (Fig. 1c, Supplementary Fig. 15).

We next investigated the prebiotic co-oligomerization of nucleobase-functionalized hydroxy acids ( $\left.\mathrm{Nu}^{\mathrm{HA}} ; \mathrm{Nu}=\mathrm{Cy}, \mathrm{Ad}, \mathrm{Mel}\right)$ with aspartic acid (abbreviated as D), an amino acid which is formed concomitantly with cyanuric acid, adenine, and melamine. ${ }^{39}$ It was previously found that the co-oligomerization of amino acids and hydroxy acids by wet-dry cycling produces oligopeptides with N-terminal hydroxy acid residues. ${ }^{49}$ We reasoned that wet-dry cycling of $\mathrm{Nu}^{\mathrm{HA}}$ species with aspartic acid would produce short oligomers of the form $\mathrm{Nu}^{\mathrm{HA}}-\mathrm{D}_{\mathrm{n}}$, and aspartic acid was chosen for this model system so that the depsipeptide oligomers would contain ionizable residues to maintain solubility in water. The formation of $\mathrm{Nu}^{\mathrm{HA}}-\mathrm{D}_{\mathrm{n}}$ oligomers proceeds by an initial acid-catalyzed esterification of $\mathrm{Nu}^{\mathrm{HA}}$ to form $\left(\mathrm{Nu}^{\mathrm{HA}}\right)_{2}$ species, which are then aminolyzed by aspartic acid to form $\mathrm{Nu}^{\mathrm{HA}}-\mathrm{D}$ (Fig. $\left.1 \mathrm{~d}\right)$. This heterodimer can be further elongated by esterification of the C-terminus (at either the $\alpha$ - or 
$\beta$-carboxylic acid of aspartic acid) and subsequent ester aminolysis by another molecule of aspartic acid.

Subjecting any of the $\mathrm{Nu}^{\mathrm{HA}}$ compounds (prepared by conventional organic synthesis for these experiments; see Section II of the Supplementary Information) and one equivalent of aspartic acid to wet-dry cycling at $85{ }^{\circ} \mathrm{C}$ for 7 cycles (i.e., one instance of rehydration per day, followed by drying at $85^{\circ} \mathrm{C}$ for 24 hours) gives only an insignificant amount of product (Supplementary Figs 16-20). We attribute the poor yields of these reactions to the physical state of the dried residues, which appear as white powders. In this solid, microcrystalline state, diffusion cannot occur, and reactive moieties therefore do not encounter each other. We reasoned that the addition of a volatile, mildly basic co-solvent might maintain hydroxy acid solubility as the sample dried (without changing the $\mathrm{pH}$ significantly) to eventually give a glass-like state in which diffusion could occur, thereby enabling the reaction. Because aromatic compounds, including heteroaromatics, are abundant in carbonaceous meteorites ${ }^{5-51}$ and are commonly produced in model prebiotic reactions, ${ }^{52-53}$ we selected pyridine as a model heterocyclic compound for these wet-dry cycling reactions. Including 8 equivalents of pyridine in the reaction of $\mathrm{Cy}^{\mathrm{HA}}$ with aspartic acid changed the physical state of the dried pellet to a glass-like semi-solid. Comparison of the UV-LC/MS chromatograms of these reactions showed that the addition of pyridine significantly increased the formation of Cy ${ }^{\mathrm{HA}}-\mathrm{D}$ (Supplementary Fig. 16). The physical state of the reactions of $\mathrm{Ad}^{\mathrm{HA}}$ and $\mathrm{Mel}^{\mathrm{HA}}$ with aspartic acid changed slightly by the addition of pyridine, but the formation of Ad ${ }^{\mathrm{HA}}-\mathrm{D}$ and $\mathrm{Mel}^{\mathrm{HA}}$-D remained low (Supplementary Figs 17 and 18). However, when wet-dry cycling reactions were performed with mixtures of $\mathrm{Cy}^{\mathrm{HA}}$ and one of its pairing partners $\left(\mathrm{Ad}^{\mathrm{HA}}\right.$ or $\mathrm{Mel}^{\mathrm{HA}}$ ) with aspartic acid and 8 equivalents of pyridine, the formation of Ad ${ }^{\mathrm{HA}}-\mathrm{D}$ and Mel ${ }^{\mathrm{HA}}$. 
D improved to amounts comparable with those found for CyHA-D (Supplementary Figs 19 and 20).

\section{Prebiotic Oligomerization of Model Proto-Nucleic Acid Monomers}

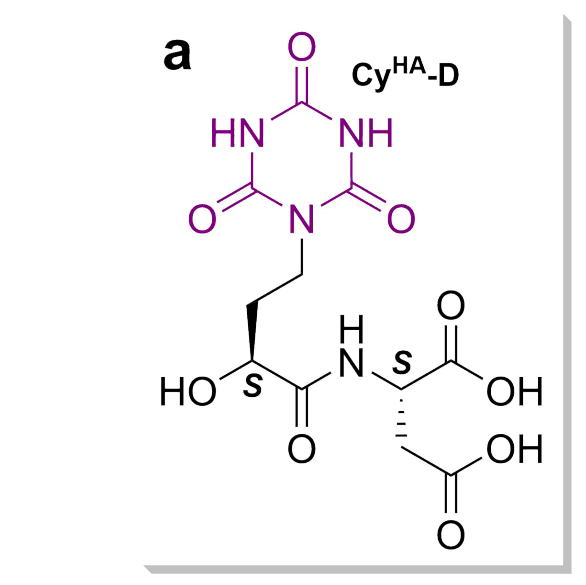

d

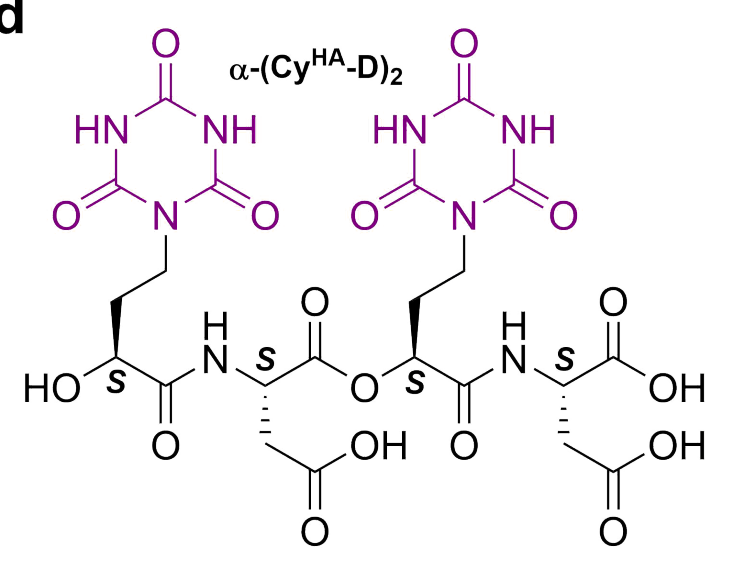

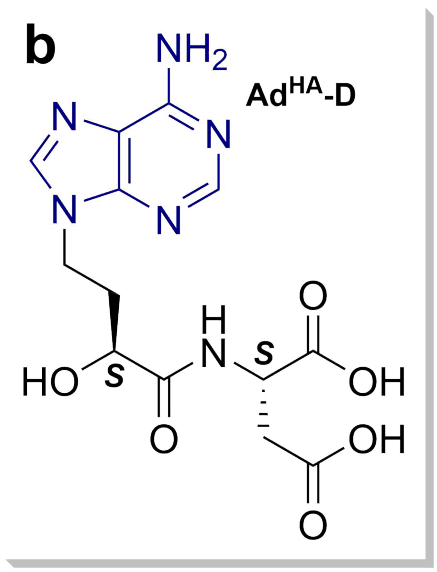<smiles>Nc1nc(N)nc(NCC[C@@H](O)C(=O)N[C@@H](CC(=O)O)C(=O)O)n1</smiles>

$\mathbf{e}$<smiles>O=C=O</smiles>

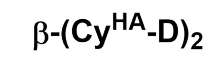<smiles>NC(=O)[C@H](CCn1cnc(=O)[nH]c1=O)OC(=O)C[C@H](NC(=O)[C@H](O)CCn1c(=O)[nH]c(=O)[nH]c1=O)C(=O)O</smiles><smiles>CCCC(=O)O</smiles>

Figure 2 | Structures of the three model proto-nucleic acid monomers and two model dimers used in this study. a,

$(S, S)-C y^{\mathrm{HA}}-\mathrm{D}$, a heterodimer of $\mathrm{Cy}{ }^{\mathrm{HA}}$ and aspartic acid. b, $(S, S)$-AdHA-D, a heterodimer of $\mathrm{Ad}^{\mathrm{HA}}$ and aspartic acid. $\mathbf{c},(S, S)$-Mel ${ }^{\mathrm{HA}}-$ D, a heterodimer of MelHA and aspartic acid. $\mathbf{d}, \alpha-(S, S, S, S)-\left(\mathrm{Cy} y^{\mathrm{HA}}-\mathrm{D}\right)_{2}$, a dimer of CyHA-D in which the two units are linked by esterification of the $\alpha$-carboxylic acid of the first aspartic acid residue. e, $\beta-(S, S, S, S)-(\mathrm{Cy} H \mathrm{HA}-\mathrm{D})_{2}$, a dimer of CyHA-D in which the two units are linked by esterification of the $\beta$-carboxylic acid of the first aspartic acid residue. Not that in the 
nomenclature of the current study, the model proto-nucleic acid monomers are themselves hydroxy acid-amino acid heterodimers, and the model dimers are heterotetramers.

To further investigate the potential for oligomerization of this proto-nucleic acid system, we synthesized and isolated $(S, S)-\mathrm{Cy}^{\mathrm{HA}}-\mathrm{D}$ (Fig. 2a), $(S, S)-\mathrm{Ad}^{\mathrm{HA}}-\mathrm{D}$ (Fig. 2b), and $(S, S)$ $\mathrm{Mel}^{\mathrm{HA}}$-D (Fig. 2c) by conventional organic synthesis. These compounds, which serve as model proto-nucleic acid monomers, are expected to oligomerize by esterification to form depsipeptides when subjected to dry-down conditions at elevated temperature and mildly acidic pH (Fig. 3a). This esterification reaction can proceed either directly at the $\alpha$-carboxylic acid of the aspartic acid moiety or through intermediate lactonization to form morpholine2,5-diones, to produce a backbone with a 6-atom repeat. This backbone may assume conformations that facilitate self-assembly by presenting nucleobases and solubilizing carboxylates on alternating sides of the depsipeptide chain, and is geometrically similar to previously studied oligopeptide nucleic acid systems that were found to support base pairing. ${ }^{27,54-55}$ Competing $\beta$-esterification produces a 7-atom segment in the backbone of the nascent informational oligomer. This segment may also access conformations that permit self-assembly. It is possible for $\alpha$-esters and $\beta$-esters to be present in the same oligomer in either a linear or a branched manner.

As with the coupling of the nucleobase-functionalized hydroxy acids to aspartic acid, the addition of a small heterocyclic compound increases the efficiency of oligomerization of the model proto-RNA monomers. For these dry-down oligomerization reactions, 2hydroxypyridine, 2-mercaptopyridine, pyridine, and pyrimidine were assessed as additives. Pyridine derivatives, including 2-hydroxypyridine, have been identified in meteorites. ${ }^{51,56}$ Pyrimidine may be produced prebiotically from acrylonitrile.57 2-Hydroxypyridine (and, by 
analogy, 2-mercaptopyridine) was chosen for its propensity to act as a bifunctional catalyst in ester aminolysis reactions, ${ }^{58}$ which may also enhance the extent of the esterification reaction (Supplementary Fig. 21). Unlike pyridine, 2-hydroxypyridine and 2mercaptopyridine and non-volatile and non-basic. Therefore, pyrimidine was tested because it allows a reasonable comparison to be made with pyridine with regard to basicity: both compounds are liquids with boiling points close to $120^{\circ} \mathrm{C}$; however, pyrimidine is less basic than pyridine. Initial screenings were performed by drying the aqueous solutions of $\mathrm{Nu}^{\mathrm{HA}}-\mathrm{D}$ compounds with heterocyclic additives and maintaining them in a dry state at $85^{\circ} \mathrm{C}$ for one week. All four of the heterocycles tested showed some enhancement of oligomerization. For the volatile compounds pyridine and pyrimidine, the extent of oligomerization increased with higher loadings (Supplementary Figs 22 and 23). For the non-volatile compounds 2hydroxypyridine and 2-mercaptopyridine, an optimum loading of one equivalent was determined. Reactions containing 2-mercaptopyridine showed the significant formation of degradation products resulting from amide hydrolysis and subsequent ester aminolysis (Supplementary Fig. 24). One equivalent of 2-hydroxypyridine was found to be effective at enhancing the extent of oligomerization without degradation (Supplementary Fig. 25). It was further found that longer reaction times gave greater extents of oligomerization, with the greatest conversion of monomer observed with one equivalent of 2 -hydroxypyridine after 8 weeks (Supplementary Fig. 26). The UV-LC/MS analyses of these oligomerization reactions are shown in Figure 3b-f.

Of the three model proto-nucleic acid monomers studied, $\mathrm{Cy}{ }^{\mathrm{HA}}-\mathrm{D}$ oligomerized the most efficiently, with oligomers detected up to 8 units in length. Ad ${ }^{\mathrm{HA}}$-D oligomerizes poorly; only dimers were detected. $\mathrm{Mel}^{\mathrm{HA}}$-D oligomerizes with intermediate efficiency, with 
oligomers detected up to 5 units in length. In the most prebiotically relevant scenario, these monomers would be present in the same mixture so that oligomers of mixed sequence could be formed. When СyHA-D was co-oligomerized with either of its potential pairing partners, $\mathrm{Ad}^{\mathrm{HA}}-\mathrm{D}$ or $\mathrm{Mel}^{\mathrm{HA}}-\mathrm{D}$, mixed-sequence oligomers up to 4 units in length were detected. Assuming comparable ionization efficiencies, the ion abundances of the tetramers from these reactions approximate a binomial distribution in which incorporation of either monomer is equally likely. For the co-oligomerization of Cy ${ }^{\mathrm{HA}}-\mathrm{D}$ with $\mathrm{Mel}^{\mathrm{HA}}-\mathrm{D}$, this binomial approximation is very accurate (Fig. 3f, inset). For the co-oligomerization of Cy ${ }^{\mathrm{HA}}-\mathrm{D}$ with $\mathrm{Ad}^{\mathrm{HA}}-\mathrm{D}$, the distribution is skewed slightly to favor oligomers enriched in $\mathrm{Cy}^{\mathrm{HA}}-\mathrm{D}$ (Fig. 3e, inset).

The results of these oligomerization reactions are similar to those found in the wetdry cycling reactions of $\mathrm{Cy}{ }^{\mathrm{HA}}, \mathrm{Ad}^{\mathrm{HA}}$, and $\mathrm{Mel}^{\mathrm{HA}}$ with aspartic acid in that the cyanuric acidfunctionalized monomer reacts more efficiently than the adenine- or melaminefunctionalized monomers. This is likely a consequence of a diminished rate of esterification in the deposited state due to the microcrystallinity of compounds containing carboxylic acid residues and adenine or melamine moieties. 

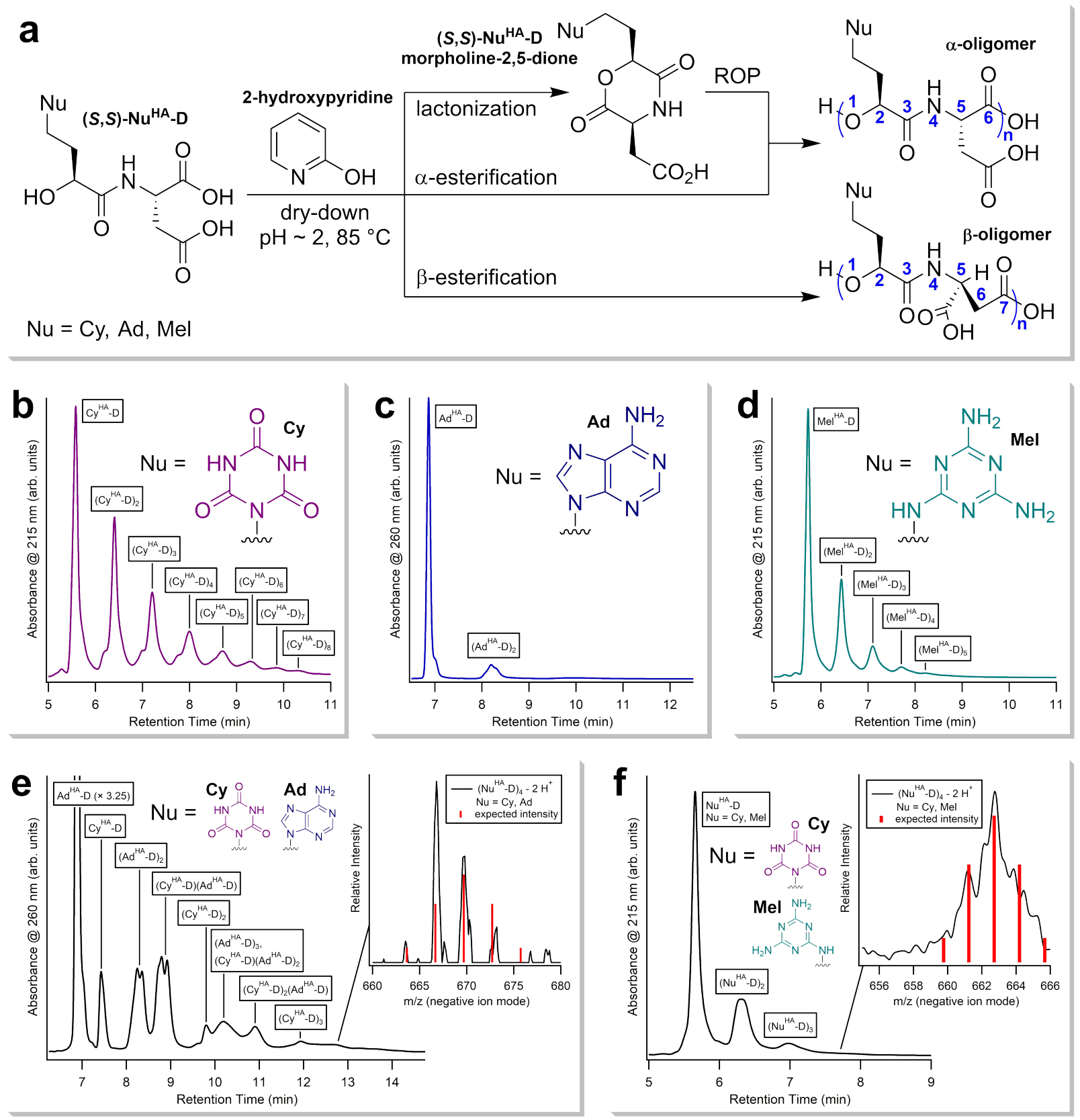

Figure 3 | UV-LC/MS analysis of the oligomerization reactions of CyHA-D, AdHA-D, and MelHA-D at $85{ }^{\circ} \mathrm{C}$ with 1 equivalent of 2-hydroxypyridine after 8 weeks. a, Prebiotic oligomerization of model monomers. When dried from an acidic aqueous solution containing a heterocyclic additive, oligomerization by esterification occurs. Two backbone linkages are possible: the $\alpha$-linkage, formed by ring-opening polymerization of the morpholine-2,5-dione form of the monomer, or by direct $\alpha$-esterification, and the $\beta$-linkage, formed by direct $\beta$-esterification. b, UV chromatogram of CyHA-D

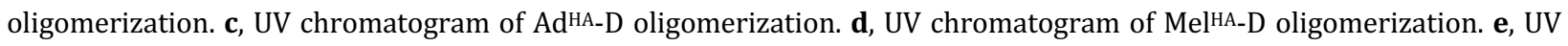
chromatogram of mixed oligomerization of 1:1 CyHA-D:AdHA-D scaled by a factor of 3.25 relative to the height of the AdHA-D 
peak. Oligomers of mixed sequence up to 4 units in length are detectable (inset) with abundances slightly offset from those predicted by a binomial distribution with equal probabilities of incorporation of each monomer. f, UV chromatogram of mixed oligomerization of 1:1 CуНА-D:Mel ${ }^{\mathrm{HA}}$-D. Oligomers of mixed sequence up to 4 units in length are detectable (inset) with abundances similar to those predicted by a binomial distribution with equal probabilities of incorporation of each monomer. In all cases, species are labeled according to the masses identified.

\section{Self-Assembly of Depsipeptide Nucleic Acids}

With the confirmation of the ability of these monomers to oligomerize by esterification in a plausibly prebiotic manner, we next turned to molecular self-assembly studies to determine whether the monomers or oligomers form pairing systems in water. Derivatives of cyanuric acid and melamine have been shown to form hexad-based supramolecular assemblies in water. ${ }^{11}$ Each hexad contains three cyanuric acid units and three melamine units, with each nucleobase interacting with two complementary nucleobases to create a highly regular structure with three-fold rotational symmetry. These planar, hydrophobic hexads stack in water to form micron-length supramolecular fibers when one or both of the nucleobase substituents provides a solubilizing electrostatic charge (Fig. 4a).11-12 Evidence of similar structures has been presented for cyanuric acid and homoadenine oligomers, in which a hexad motif has also been proposed, but with a less regular structure due to the reduced structure symmetry of adenine. ${ }^{40-42}$ Although this hexad mode of self-assembly is distinct from the familiar duplex mode of extant nucleic acids, information transfer by complementary base pairing is still possible, and the considerable stability of supramolecular structures associated with the hexad motif may have provided an evolutionarily advantage that, historically, allowed hexad-based self-assembly to precede duplex-based self-assembly. 
With charged backbone moieties, stacked-hexad supramolecular fibers remain soluble; however, their tumbling rates in solution are so slow that their ${ }^{1} \mathrm{H}$ NMR signals broaden to baseline, leaving only the remaining unassembled molecules detectable. This phenomenon can be exploited to determine a minimum assembly concentration (MAC) that is a measure of the propensity of a given system to self-assemble: low MAC values indicate a strong propensity for self-assembly. Using this technique, ${ }^{59-60}$ MAC values were determined in $\mathrm{D}_{2} \mathrm{O}$ at $25^{\circ} \mathrm{C}, \mathrm{pD} 7.5$, with $\mathrm{MgCl}_{2} 25 \mathrm{mM}$. These conditions were chosen based on previously determined trends in supramolecular assembly with $\mathrm{pH}$ (or pD) ${ }^{11,60}$ and on the dependence of supramolecular assembly on divalent metal cations. ${ }^{40}$ Under these conditions, Mel ${ }^{\mathrm{HA}}-\mathrm{D}$ forms long, soluble assemblies with cyanuric acid with a MAC of $16.5 \mathrm{mM}$ (Fig. 4b). However, $\mathrm{Ad}^{\mathrm{HA}}-\mathrm{D}$ did not assemble with cyanuric acid (Fig. 4b). Cy ${ }^{\mathrm{HA}}-\mathrm{D}$ assembles with melamine under these conditions; however, these supramolecular aggregates precipitate from solution (Supplementary Fig. 27). No assembly was detected for Cy ${ }^{\mathrm{HA}}-\mathrm{D}$ with $\mathrm{Mel}^{\mathrm{HA}}-\mathrm{D}$ or Ad ${ }^{\mathrm{HA}}-\mathrm{D}$ (Supplementary Figs 29 and 31). 

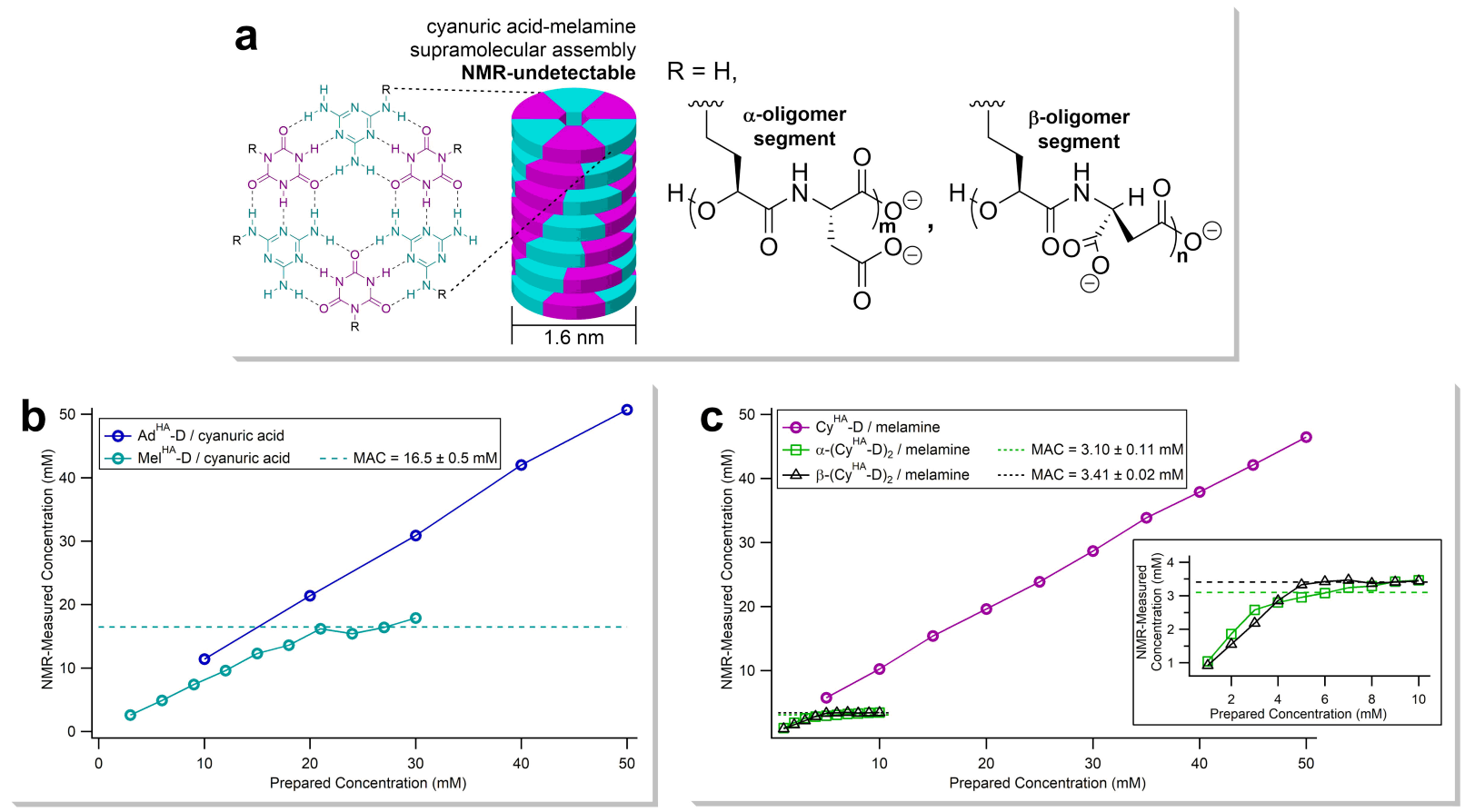

Figure 4 |배 NMR analysis of the self-assembly of cyanuric-melamine systems and cyanuric acid-adenine systems.

a, When cyanuric acid derivatives are incubated in water with melamine derivatives (or adenine derivatives) under certain conditions of temperature, $\mathrm{pH}$, and ionic strength, self-assembly can occur to form supramolecular fibers. This supramolecular assembly forms after a critical concentration, the minimum assembly concentration (MAC), has been reached. Unassembled molecules remain detectable by NMR, but assembled molecules do not, allowing the MAC to be

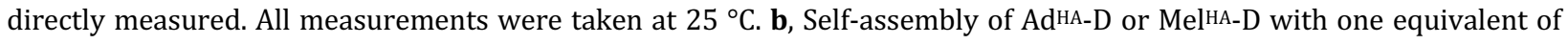
cyanuric acid in $\mathrm{D}_{2} \mathrm{O}$, pD 7.5, with $\mathrm{MgCl}_{2} 25$ mM. AdHA-D does not assemble below 50 mM; MelHA-D assembles with a MAC of 16.5 mM. c, Self-assembly of CyHA-D, $\alpha-(\text { CyHA-D })_{2}$, or $\beta-(\text { CyHA-D })_{2}$ with melamine in $\mathrm{D}_{2} \mathrm{O}$, pD 6.5. CyHA-D was incubated with one equivalent of melamine, while $\alpha-(\text { CyHA-D })_{2}$ and $\beta-(\text { Сун-D })_{2}$, with two cyanuric acid moieties for each, were incubated with two equivalents of melamine. СуHА-D does not assemble below $50 \mathrm{mM} \alpha-(\mathrm{CyHA}-\mathrm{D})_{2}$ and $\beta$-(CyHA-D $)_{2}$ assemble with MAC values of $3.10 \mathrm{mM}$ and $3.41 \mathrm{mM}$, respectively (inset).

Although the monomers did not consistently show propensity for self-assembly, this does not preclude the oligomers from undergoing self-assembly. To study this, the dimers of Cy ${ }^{\mathrm{HA}}-\mathrm{D}$ (the monomer which oligomerized to the greatest extent) were isolated. As expected, two main species were formed: the $\alpha$-ester, $\alpha-\left(\mathrm{Cy}^{\mathrm{HA}}-\mathrm{D}\right)_{2}$ (Fig. $\left.2 \mathrm{~d}\right)$, and the $\beta$-ester, $\beta$ - $\left(\mathrm{C} \mathrm{y}^{\mathrm{HA}}{ }_{-}\right.$ 
D) 2 (Fig. 2e). The identities of these compounds were assigned based on the ${ }^{1} \mathrm{H}$ NMR chemical shifts of the $\alpha$ - and $\beta$-protons of the aspartic acid residues, which shift downfield when the adjacent carboxylic acid residues are esterified (Supplementary Fig. 3). Compounds $\alpha-\left(C y^{\mathrm{HA}}-\mathrm{D}\right)_{2}$ and $\beta-\left(\mathrm{Cy}^{\mathrm{HA}}-\mathrm{D}\right)_{2}$ were isolated in a relative yield of $2: 1$ (respectively), suggesting that the mechanism of oligomerization by lactonization and nucleophilic ring-opening was operative, but not exclusively (Fig. 3a).

For either of these dimers to self-assemble in the stacked-hexad motif, the cyanuric acid residues must point in the same direction (into the assembly), while the solubilizing carboxylate residues must face opposite the cyanuric acid residues (into the solvent). These criteria are met in the fully extended backbone conformation of $\alpha$ - $(\mathrm{CyHA}-\mathrm{D})_{2}$, where all dihedral angles are $180^{\circ}$. However, for $\beta-\left(\mathrm{C} y^{\mathrm{HA}}-\mathrm{D}\right)_{2}$, these criteria can only be met with a distorted backbone conformation containing at least three bonds with dihedral angles deviating from $180^{\circ}$, potentially introducing steric strain. Nevertheless, $\alpha-\left(C y^{\mathrm{HA}}-\mathrm{D}\right)_{2}$ and $\beta$ (Cy $\left.{ }^{\mathrm{HA}}-\mathrm{D}\right)_{2}$ both form assemblies with melamine: at pD 6.5, with no divalent metal ion present, MAC values of about $3 \mathrm{mM}$ were determined for both dimers (Fig. 4c, inset). These slightly modified conditions were employed to preemptively attenuate ester hydrolysis, which may be accelerated by slightly basic $\mathrm{pH}$ and by divalent metal cations. ${ }^{61}$ The product of this potential hydrolysis, $\mathrm{Cy}^{\mathrm{HA}}-\mathrm{D}$, did not assemble (or precipitate) with melamine under these conditions (Fig. 4c). These positive results for the dimers of $\mathrm{Cy}^{\mathrm{HA}}$-D suggest that both 6-atom and 7-atom depsipeptide backbone segments can adopt conformations that permit assembly. No assemblies of either $\alpha-\left(C y^{\mathrm{HA}}-\mathrm{D}\right)_{2}$ or $\beta-\left(\mathrm{C} y^{\mathrm{HA}}-\mathrm{D}\right)_{2}$ with adenine were detected at concentrations up to $20 \mathrm{mM}$ under these conditions (Supplementary Fig. 33). 

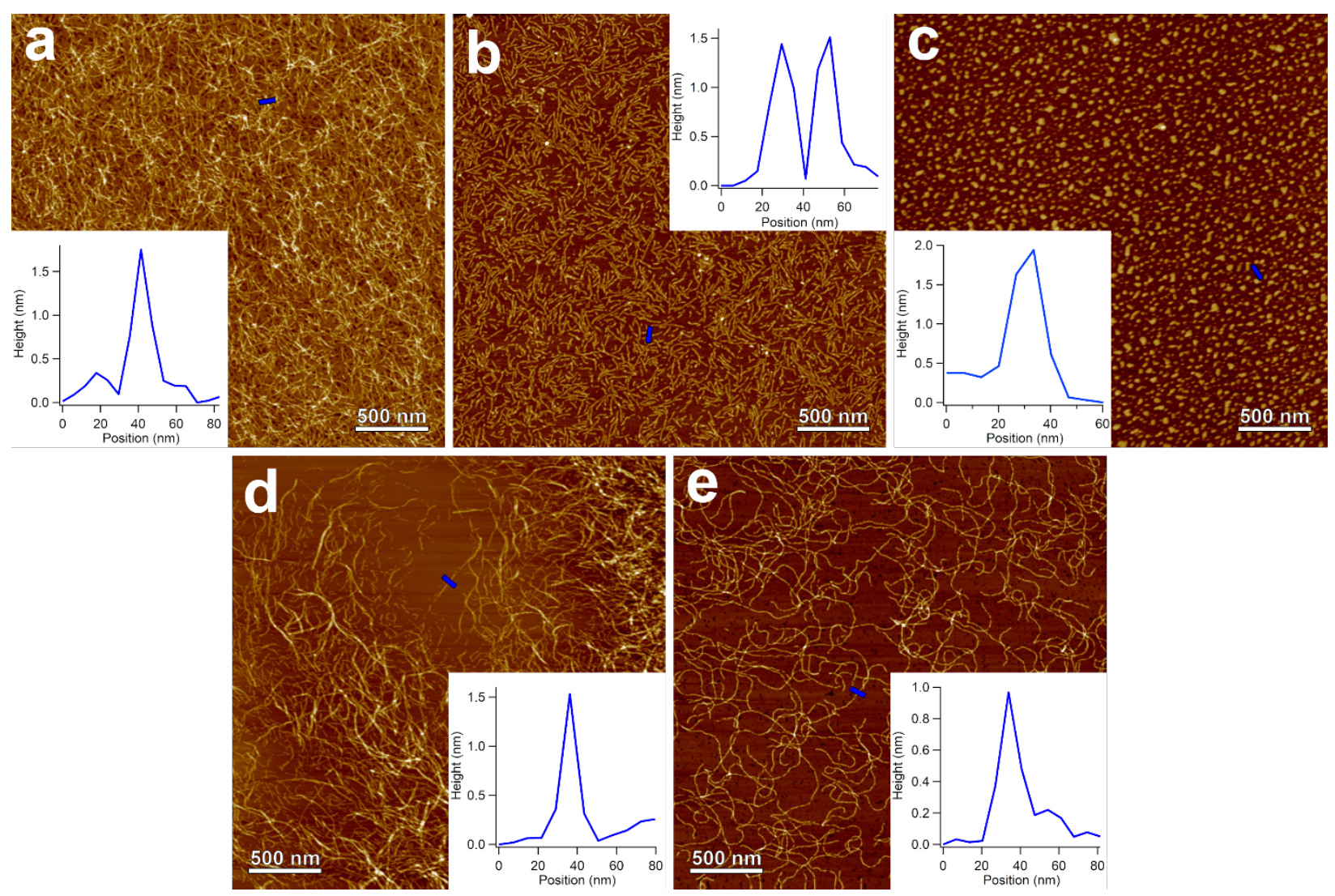

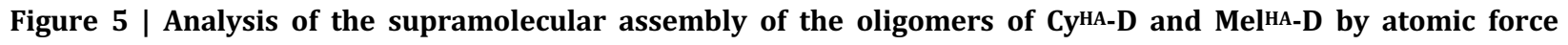
microscopy. a, Topographical image of oligo-(СунА-D) paired with melamine, $\mathrm{pD}$ 6.5. In this panel, and others, insets show fiber height measurements taken across blue bar. b, Topographical image of oligo-(MelHA-D) oligomers paired with cyanuric acid, pD 6.5. c, Topographical image of co-oligomers of CyHA-D and MelHA-D with no externally added underivatized pairing heterocycle, pD 7.5, $\mathrm{MgCl}_{2} 25$ mM. d, Topographical image of $\alpha-(\mathrm{CyHA-D})_{2}$ paired with melamine, pD 6.5. E, Topographical image of $\beta-(\text { CyHA-D })_{2}$ paired with melamine, $\mathrm{pD} 6.5$.

The assemblies were next investigated by atomic force microscopy (AFM). Samples of oligomerized $\mathrm{Cy}^{\mathrm{HA}}-\mathrm{D}, \mathrm{Mel}^{\mathrm{HA}}-\mathrm{D}$, and $\mathrm{Ad}^{\mathrm{HA}}-\mathrm{D}$ (dry state, 1 eq. 2 -hydroxypyridine, $85^{\circ} \mathrm{C}$, two weeks) were incubated with their complement (either melamine or adenine for Cy ${ }^{\mathrm{HA}}-\mathrm{D}$ oligomers, or cyanuric acid for oligomers of $\mathrm{Mel}^{\mathrm{HA}}-\mathrm{D}$ and $\mathrm{Ad}^{\mathrm{HA}}-\mathrm{D}$ ) in $\mathrm{D}_{2} \mathrm{O}$ at $\mathrm{pD}$ 6.5; conditions for which no assembly was observed by ${ }^{1} \mathrm{H}$ NMR spectroscopy for monomeric Cy ${ }^{\mathrm{HA}}-\mathrm{D}, \mathrm{Ad}^{\mathrm{HA}}$ 
D, or Mel ${ }^{\mathrm{HA}}-\mathrm{D}$ (Fig. 4c, Supplementary Figs 28-31). The cyanuric acid-melamine system shows a stronger propensity for self-assembly than the cyanuric acid-adenine system. While no fibers were detected for oligo-(AdHA-D) with cyanuric acid (Supplementary Fig. 42), long fibers are formed from the assembly of oligo-(CyHA-D) with melamine (Fig. 5a) or from the assembly of oligo-( $\left.\mathrm{Mel}^{\mathrm{HA}}-\mathrm{D}\right)$ with cyanuric acid (Fig. 5b). The heights of these assemblies (Fig. 5a,b, insets) match the predicted value for the stacked-hexad motif of $1.6 \mathrm{~nm}$ (Fig. 4a). Co-oligomers formed from $\mathrm{Cy}^{\mathrm{HA}}-\mathrm{D}$ and $\mathrm{Mel}^{\mathrm{HA}}-\mathrm{D}$ (dry state, 1 eq. 2-hydroxypyridine, $85^{\circ} \mathrm{C}$, two weeks), assembled in the absence of an underivatized base at pD 7.5 with $\mathrm{MgCl}_{2}$ $25 \mathrm{mM}$, mostly forming nonlinear aggregates (Fig. 5c). Assuming that this assembly still occurs by the stacked-hexad motif, these aggregates contain six charged backbones whose electrostatic repulsion may inhibit the formation of long fibers. The heights of the interspersed short linear assemblies are slightly greater than $1.6 \mathrm{~nm}$ (Fig. 5c, inset), possibly also due to the presence of six backbones in one assembly.

Long fibers could also be observed for both $\alpha-\left(\mathrm{C} y^{\mathrm{HA}}-\mathrm{D}\right)_{2}$ and $\beta-\left(\mathrm{C} y^{\mathrm{HA}}-\mathrm{D}\right)_{2}$ with melamine at pD 6.5 (with no divalent metal cation). The $1.6 \mathrm{~nm}$ height (Fig. $5 \mathrm{~d}$, inset) of the linear assemblies formed from $\alpha-\left(\mathrm{Cy}^{\mathrm{HA}}-\mathrm{D}\right)_{2}$ with melamine (Fig. 5d) is consistent with a stacked-hexad motif; however, assemblies formed from $\beta-\left(C y^{\mathrm{HA}}-\mathrm{D}\right)_{2}$ with melamine (Fig. 5e) showed a height of $1.0 \mathrm{~nm}$ (Fig. 5e, inset), which could indicate a distorted or altogether different mode of self-assembly.

\section{Resistance of Depsipeptide Nucleic Acids to Hydrolysis}

Orgel suggested that the hydrolytic instability of the ester bond diminishes its viability as a backbone linkage for proto-nucleic acids. ${ }^{8}$ We performed hydrolysis studies 
using the dimers $\alpha-\left(\mathrm{Cy}^{\mathrm{HA}}-\mathrm{D}\right)_{2}$ and $\beta-\left(\mathrm{C} y^{\mathrm{HA}}-\mathrm{D}\right)_{2}$ to test whether these esters would be too unstable to sustain an early informational polymer system. The dimers were incubated (10 $\mathrm{mM}, 25{ }^{\circ} \mathrm{C}$ in $\mathrm{D}_{2} \mathrm{O}, \mathrm{pD}$ 6.5) both in the presence and absence of melamine, a gel-forming pairing partner. Over a period of 14 days, the concentrations of $\alpha-\left(C y^{\mathrm{HA}}-\mathrm{D}\right)_{2}$ or $\beta-\left(\mathrm{Cy}^{\mathrm{HA}}-\mathrm{D}\right)_{2}$ and monomeric Cy ${ }^{\mathrm{HA}}-\mathrm{D}$ were measured by UV-LC/MS (Fig. 6). It was found that the rate of hydrolysis of $\alpha-\left(C y^{\mathrm{HA}}-\mathrm{D}\right)_{2}$ diminished as the concentration of melamine increased (Fig. 6a), suggesting that $\alpha-\left(\mathrm{Cy}^{\mathrm{HA}}-\mathrm{D}\right)_{2}$ resists hydrolysis in the assembled state. Interestingly, the rate of hydrolysis of $\beta-\left(C y^{\mathrm{HA}}-\mathrm{D}\right)_{2}$ is much slower than that of $\alpha-\left(C y^{\mathrm{HA}}-\mathrm{D}\right)_{2}$, and the effect of selfassembly with melamine is insignificant (Fig. 6b) on the timescale of this experiment.

The rate expressions for the hydrolysis of $\alpha-\left(\mathrm{C} y^{\mathrm{HA}}-\mathrm{D}\right)_{2}$ or $\beta-\left(\mathrm{C} y^{\mathrm{HA}}-\mathrm{D}\right)_{2}$ in the presence of melamine are complex due to the existence of two equilibrating soluble phases (assembled and unassembled). However, a first-order approximation provides expressions for the halflives that permit reliable comparison. In the absence of melamine, $\alpha-\left(C y^{\mathrm{HA}}-\mathrm{D}\right)_{2}$ hydrolyzes with a half-life of approximately 4.5 days. With $60 \mathrm{mM}$ melamine present, this half-life increases more than 25 -fold to about 100 days. On the other hand, $\beta$-(Cy $\left.{ }^{\mathrm{HA}}-\mathrm{D}\right)_{2}$, in the presence or absence of melamine, hydrolyzes with a half-life of approximately 200 days. (See Supplementary Table 1 for all rate constants.) The faster rate of hydrolysis of $\alpha-\left(\mathrm{Cy}^{\mathrm{HA}}-\mathrm{D}\right)_{2}$ compared to $\beta-\left(C y^{\mathrm{HA}}-\mathrm{D}\right)_{2}$ can be attributed to a "backbiting" mechanism of hydrolysis (Fig. 6c). ${ }^{62}$ The terminal hydroxyl group of $\alpha-\left(\mathrm{Cy}^{\mathrm{HA}}-\mathrm{D}\right)_{2}$, acting as an intramolecular nucleophile, attacks the ester moiety to form a 6-membered ring intermediate, which ultimately produces the morpholine-2,5-dione of $\mathrm{Cy}^{\mathrm{HA}}-\mathrm{D}$ by ejecting one equivalent of monomeric $\mathrm{Cy}^{\mathrm{HA}}-\mathrm{D}$. The morpholine-2,5-dione is then hydrolyzed into a second equivalent of CyHA-D. This mechanism of hydrolysis is expected to be much less effective for $\beta-\left(C y^{\mathrm{HA}}-\mathrm{D}\right)_{2}$, as 
bioRxiv preprint doi: https://doi.org/10.1101/2020.09.01.278838; this version posted September 4, 2020. The copyright holder for this preprint (which was not certified by peer review) is the author/funder. All rights reserved. No reuse allowed without permission.

intramolecular attack of the ester by the terminal hydroxyl group must proceed through a less favorable 7-membered ring intermediate (Fig. 6d). 

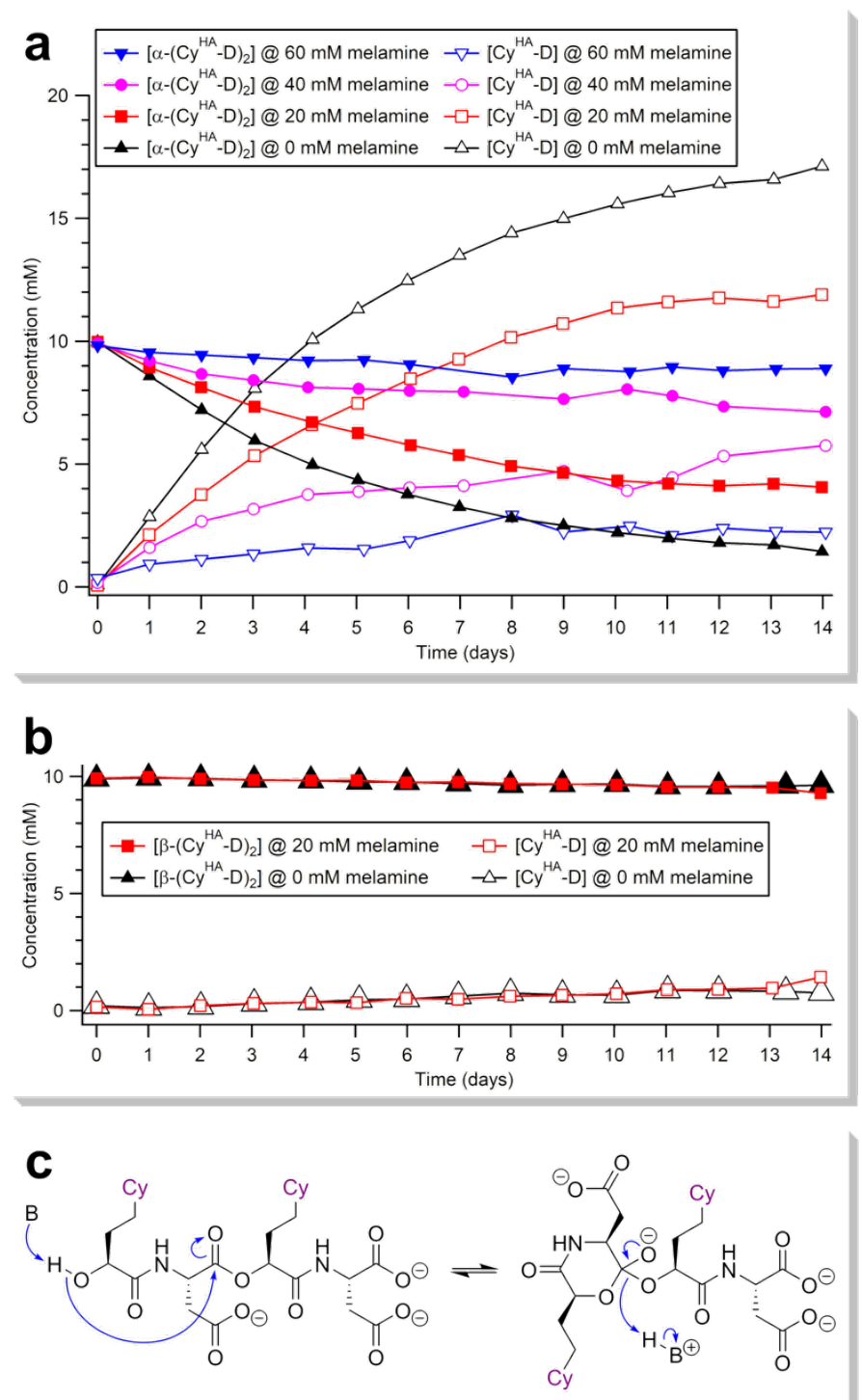

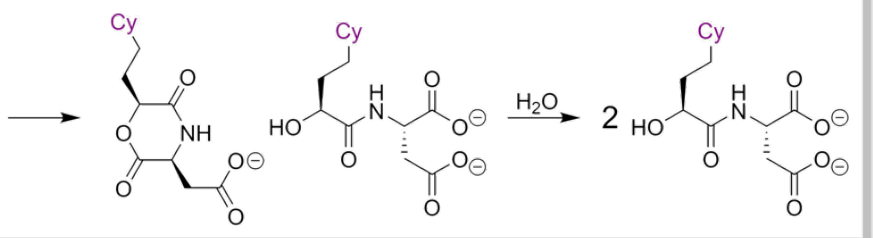

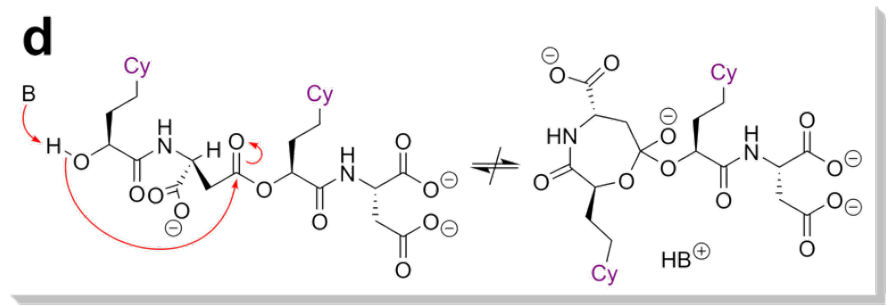

Figure 6 | Hydrolysis of (CyHA-D)2 at pD 6.5 and its inhibition by supramolecular assembly with melamine. a, Hydrolysis of $\alpha-\left(C y^{\mathrm{HA}}-\mathrm{D}\right)_{2}$ with varying concentrations of melamine. $\mathbf{b}$, Hydrolysis of $\beta-\left(\mathrm{C} y^{\mathrm{HA}}-\mathrm{D}\right)_{2}$ with or without melamine 
at $20 \mathrm{mM}$. c, The proposed mechanism of hydrolysis of $\alpha-(\text { СуHА-D })_{2}$. Base-catalyzed intramolecular attack on the ester moiety produces a 6-membered cyclic intermediate which ejects one equivalent of CyHA-D to form the morpholine-2,5-dione of Суна-D. This morpholine-2,5-dione rapidly hydrolyzes to give the second equivalent of CyHA-D. d, An analogous mechanism of hydrolysis for $\beta$-(СунА-D $)_{2}$ is unlikely to occur, as the formation of a 7 -membered cyclic intermediate is required. All reported concentrations were measured by UV-LC/MS monitoring at $215 \mathrm{~nm}$ and were normalized according to the formula $\left[(\mathrm{CyHA}-\mathrm{D})_{2}\right]+1 / 2\left[\mathrm{C} y^{\mathrm{HA}}-\mathrm{D}\right]=10 \mathrm{mM}$.

\section{Discussion}

The results presented here demonstrate that depsipeptide nucleic acids exhibit multiple properties required of a candidate proto-nucleic acid. The nucleobasefunctionalized hydroxy acids are formed in a plausibly prebiotic manner. For adenine and cyanuric acid, the corresponding $\gamma$-nucleobase-functionalized cyanohydrins are formed in one pot. For melamine, a functionalized hydroxy acid is formed from prebiotic precursors by nucleophilic aromatic substitution of a sulfur-substituted heterocycle. Additionally, either of these reactions may be generalizable for the formation of other nucleobase-functionalized hydroxy acids and amino acids. $\mathrm{Cy}^{\mathrm{HA}}-\mathrm{D}, \mathrm{Ad}^{\mathrm{HA}}-\mathrm{D}$, and $\mathrm{Mel}^{\mathrm{HA}}-\mathrm{D}$, which serve as model monomers, are formed prebiotically by wet-dry cycling reactions of the $\mathrm{Nu}^{\mathrm{HA}}$ species with aspartic acid in the presence of pyridine. These monomers oligomerize by esterification when dried from an aqueous solution with 2-hydroxypyridine at $85^{\circ} \mathrm{C}$ at a mildly acidic $\mathrm{pH}$. During this hot, dry phase, esterification is thermodynamically favorable and proceeds without the need for chemical activation. Furthermore, $\mathrm{Cy}^{\mathrm{HA}}-\mathrm{D}$ and $\mathrm{Mel}^{\mathrm{HA}}-\mathrm{D}$, and their oligomers, self-assemble in water. Importantly, the species formed from the cooligomerization of $\mathrm{Cy}^{\mathrm{HA}}-\mathrm{D}$ and $\mathrm{Mel}^{\mathrm{HA}}-\mathrm{D}$ also self-assemble, as is required for information transfer in a pre-RNA system. Finally, the hydrolysis rates of ester-linked dimers is strongly 
dependent on backbone geometry and greatly attenuated by association, which provides a mechanism for evolution by selection for enhanced hydrolytic stability.

It is important to note that prebiotic polymers formed by irreversible oligomerization may not have been amenable to chemical evolution. Reversible oligomerization provides an opportunity for error correction, which is an essential requirement, as the supply of monomers would otherwise be rapidly exhausted by "failed" sequences, preventing further evolution of the system. ${ }^{63}$ The oligomers described here are stabilized against hydrolysis by self-assembly but can also selectively be hydrolyzed to reform their component monomers. The proposed accelerated degradation by the backbiting mechanism of $\alpha-\left(\mathrm{Cy}^{\mathrm{HA}}-\mathrm{D}\right)_{2}$ compared with $\beta$-(CyHA-D $)_{2}$ has an important consequence for longer oligomers. If an $\alpha$-ester linkage is present at the $\mathrm{O}$-terminus of the depsipeptide (analogous to the $\mathrm{N}$-terminus of a peptide), backbiting will occur until a $\beta$-linkage is encountered in the oligomer. Once a $\beta$ linkage is present at the 0-terminus, the backbiting degradation mechanism is no longer operative, and any linkages (whether $\alpha$ or $\beta$ ) in the middle of the oligomer will be relatively stable to hydrolysis.

Over the past half-century, a great deal of experimental effort has been devoted to attempts to demonstrate a feasible prebiotic synthesis of canonical RNA nucleotides, the initial oligomerization of these nucleotides, and the non-enzymatic, template-directed replication of RNA oligomers. Despite this, no scenario yet exists that displays all of these phenomena. ${ }^{64}$ Our results suggest that alternative ancestral proto-nucleic acid monomers and oligomers, which can be formed and oligomerized under prebiotic conditions, hold the potential to address some of these difficulties. We hope this work will help inspire further exploration of this possibility. 


\section{Conclusion}

We have presented here a new candidate proto-nucleic acid, depsipeptide nucleic acid, which is accessible via plausible prebiotic synthesis from prebiotically available starting materials, and oligomerizes without the need for condensing agents. The depsipeptide nucleic acid displays propensity for self-assembly, and selective resistance to hydrolytic degradation upon self-assembly. These properties, combined with the reversible linker chemistry, create a system that is suitable for facilitating chemical evolution. The selfassembly of depsipeptide nucleic acid oligomers is enabled by the noncanonical nucleobases cyanuric acid and melamine, which may have preceded the extant canonical nucleobases in the evolution of RNA. ${ }^{65}$ The propensity of depsipeptide nucleic acids for oligomerization in the dry state and selective hydrolysis in the rehydrated state are inherent properties of esters. Like the nucleobase component of nucleic acids, the ester linkage, which is readily formed under prebiotic conditions, may have preceded the prebiotically challenging phosphodiester as the backbone linker of nucleic acids.

\section{References}

1. Krishnamurthy, R., Experimentally investigating the origin of DNA/RNA on early Earth. Nat. Commun. 2018, 9 (1), 5175.

2. Joyce, G. F.; Orgel, L. E., Prospects for understanding the origin of the RNA world. In The RNA World, Second Edition: The Nature of Modern RNA Suggests a Prebiotic RNA World, Gesteland, R. F.; Atkins, J. F., Eds. Cold Spring Harbor Laboratory Press: Cold Spring Harbor, NY, 1999; pp 49-77. 
3. Yadav, M.; Kumar, R.; Krishnamurthy, R., Chemistry of Abiotic Nucleotide Synthesis. Chem Rev 2020.

4. Fialho, D. M.; Roche, T. P.; Hud, N. V., Prebiotic Syntheses of Noncanonical Nucleosides and Nucleotides. Chem Rev 2020, 120 (11), 4806-4830.

5. Hud, N. V., Searching for lost nucleotides of the pre-RNA World with a self-refining model of early Earth. Nat. Commun. 2018, 9 (1), 5171.

6. Hud, N. V.; Cafferty, B. J.; Krishnamurthy, R.; Williams, L. D., The origin of RNA and 'My Grandfather's Axe'. Chem. Biol. 2013, 20, 466-474.

7. Cleaves, H. J.; Bada, J. L., The Prebiotic Chemistry of Alternative Nucleic Acids. In Genesis - In The Beginning: Precursors of Life, Chemical Models and Early Biological Evolution, Seckbach, J., Ed. Springer Science+Business Media Dordrecht: 2012; pp 3-33.

8. Orgel, L. E., Some consequences of the RNA world hypothesis. Orig. Life Evol. B. 2003, 33 (2), 211-218.

9. Joyce, G. F.; Schwartz, A. W.; Miller, S. L.; Orgel, L. E., The case for an ancestral genetic system involving simple analogs of the nucleotides. Proc. Natl. Acad. Sci. USA 1987, 84 (13), 4398-402.

10. Chen, M. C.; Cafferty, B. J.; Mamajanov, I.; Gállego, I.; Khanam, J.; Krishnamurthy, R.; Hud, N. V., Spontaneous prebiotic formation of a $\beta$-ribofuranoside that self-assembles with a complementary heterocycle. J. Am. Chem. Soc. 2014, 136 (15), 5640-5646.

11. Ma, M.; Bong, D., Determinants of cyanuric acid and melamine assembly in water. Langmuir 2011, 27 (14), 8841-53. 
12. Cafferty, B. J.; Fialho, D. M.; Khanam, J.; Krishnamurthy, R.; Hud, N. V., Spontaneous formation and base pairing of plausible prebiotic nucleotides in water. Nat. Commun. 2016, $7,11328$.

13. Fialho, D. M.; Clarke, K. C.; Moore, M. K.; Schuster, G. B.; Krishnamurthy, R.; Hud, N. V., Glycosylation of a model proto-RNA nucleobase with non-ribose sugars: implications for the prebiotic synthesis of nucleosides. Org. Biomol. Chem. 2018, 16, 1263-1271.

14. Kolb, V. M.; Dworkin, J. P.; Miller, S. L., Alternative bases in the RNA world: The prebiotic synthesis of urazole and its ribosides. J. Mol. Evol. 1994, 38, 549-557.

15. Bean, H. D.; Sheng, Y. H.; Collins, J. P.; Anet, F. A. L.; Leszczynski, J.; Hud, N. V., Formation of a $\beta$-pyrimidine nucleoside by a free pyrimidine base and ribose in a plausible prebiotic reaction. J. Am. Chem. Soc. 2007, 129, 9556-9557

16. Kim, H. J.; Benner, S. A., Prebiotic glycosylation of uracil with electron-donating substituents. Astrobiology 2015, 15 (4), 301-6.

17. Becker, S.; Schneider, C.; Okamura, H.; Crisp, A.; Amatov, T.; Dejmek, M.; Carell, T., Wetdry cycles enable the parallel origin of canonical and non-canonical nucleosides by continuous synthesis. Nat. Commun. 2018, 9 (1), 163.

18. Gonzalez, M. A.; Requejo, J. L. J.; Albarran, J. C. P.; Perez, J. A. G., Facile preparation of C-glycosylbarbiturates and C-glycosylbarbituric acids. Carbohydr. Res. 1986, 158, 53-66.

19. Eschenmoser, A., Chemical etiology of nucleic acid structure. Science 1999, 284 (5423), 2118-2124.

20. Pinheiro, V. B.; Taylor, A. I.; Cozens, C.; Abramov, M.; Renders, M.; Zhang, S.; Chaput, J. C.; Wengel, J.; Peak-Chew, S. Y.; McLaughlin, S. H.; Herdewijn, P.; Holliger, P., Synthetic genetic polymers capable of heredity and evolution. Science 2012, 336 (6079), 341-344. 
21. Keefe, A. D.; Miller, S. L., Are polyphosphates or phosphate esters prebiotic reagents? J. Mol. Evol. 1995, 41, 693-702.

22. Lohrmann, R.; Orgel, L. E., Urea-inorganic phosphate mixtures as prebiotic phosphorylating agents. Science 1971, 171 (3970), 490-494.

23. Burcar, B.; Pasek, M.; Gull, M.; Cafferty, B. J.; Velasco, F.; Hud, N. V.; Menor-Salván, C., Darwin's Warm Little Pond: A one-pot reaction for prebiotic phosphorylation and the mobilization of phosphate from minerals in a urea-based solvent. Angew Chem Int Ed Engl 2016, 55, 13249-13253.

24. Gibard, C.; Bhowmik, S.; Karki, M.; Kim, E. K.; Krishnamurthy, R., Phosphorylation, oligomerization and self-assembly in water under potential prebiotic conditions. Nat Chem 2018, 10 (2), 212-217.

25. Bean, H. D.; Anet, F. A. L.; Gould, I. R.; Hud, N. V., Glyoxylate as a backbone linkage for a prebiotic ancestor of RNA. Orig. Life Evol. B. 2006, 36 (1), 39-63.

26. Nelson, K. E.; Levy, M.; Miller, S. L., Peptide nucleic acids rather than RNA may have been the first genetic molecule. Proc. Natl. Acad. Sci. USA 2000, 97 (8), 3868-3871.

27. Mittapalli, G. K.; Reddy, K. R.; Xiong, H.; Munoz, O.; Han, B.; De Riccardis, F.; Krishnamurthy, R.; Eschenmoser, A., Mapping the landscape of potentially primordial informational oligomers: oligodipeptides and oligodipeptoids tagged with triazines as recognition elements. Angew. Chem., Int. Ed. Engl. 2007, 46 (14), 2470-2477.

28. De Graaf, R. M.; Schwartz, A. W., Thermal synthesis of nucleoside H-phosphonates under mild conditions. Orig. Life Evol. B. 2005, 35 (1), 1-10.

29. Lonnberg, T., Sulfurization of H-Phosphonate Diesters by Elemental Sulfur under Aqueous Conditions. Acs Omega 2017, 2 (8), 5122-5127. 
30. Harada, K.; Orgel, L. E., Template-Directed Oligomerization of 5'-Deoxy-5'Nucleosideacetic Acid-Derivatives. Orig. Life Evol. B. 1990, 20 (2), 151-160.

31. Halford, M. H.; Jones, A. S., Synthetic analogues of polynucleotides. Nature 1968, 217 (5129), 638-40.

32. Mamajanov, I.; MacDonald, P. J.; Ying, J.; Duncanson, D. M.; Dowdy, G. R.; Walker, C. A.; Engelhart, A. E.; Fernández, F. M.; Grover, M. A.; Hud, N. V.; Schork, F. J., Ester formation and hydrolysis during wet-dry cycles: generation of far-from-equilibrium polymers in a model prebiotic reaction. Macromolecules 2014, 47, 1334-1343.

33. Forsythe, J. G.; Yu, S. S.; Mamajanov, I.; Grover, M. A.; Krishnamurthy, R.; Fernandez, F. M.; Hud, N. V., Ester-Mediated Amide Bond Formation Driven by Wet-Dry Cycles: A Possible Path to Polypeptides on the Prebiotic Earth. Angew. Chem., Int. Ed. Engl. 2015, 54 (34), 98719875.

34. Yu, S. S.; Krishnamurthy, R.; Fernandez, F. M.; Hud, N. V.; Schork, F. J.; Grover, M. A., Kinetics of prebiotic depsipeptide formation from the ester-amide exchange reaction. Phys. Chem. Chem. Phys. 2016, 18 (41), 28441-28450.

35. Cleaves, H. J., The Prebiotic Synthesis of Acrolein. Monatshefte für Chemie 2003, 134 (4), 585-593.

36. Cleaves, H. J., The Reactions of Nitrogen Heterocycles with Acrolein: Scope and Prebiotic Significance. Astrobiology 2002, 2 (4), 403-415.

37. Van Trump, J. E.; Miller, S. L., Prebiotic synthesis of methionine. Science 1972, 178 (4063), 859-60. 
38. Rodriguez, L. E.; House, C. H.; Smith, K. E.; Roberts, M. R.; Callahan, M. P., Nitrogen heterocycles form peptide nucleic acid precursors in complex prebiotic mixtures. Sci Rep 2019, $9(1), 9281$.

39. Menor-Salvan, C.; Ruiz-Bermejo, D. M.; Guzman, M. I.; Osuna-Esteban, S.; VeintemillasVerdaguer, S., Synthesis of pyrimidines and triazines in ice: Implications for the prebiotic chemistry of nucleobases. Chem. Eur. J. 2009, 15 (17), 4411-4418.

40. Avakyan, N.; Greschner, A. A.; Aldaye, F.; Serpell, C. J.; Toader, V.; Petitjean, A.; Sleiman, H. F., Reprogramming the assembly of unmodified DNA with a small molecule. Nat. Chem. 2016, $8(4), 368-376$.

41. Li, C.; Cafferty, B. J.; Karunakaran, S. C.; Schuster, G. B.; Hud, N. V., Formation of supramolecular assemblies and liquid crystals by purine nucleobases and cyanuric acid in water: implications for the possible origins of RNA. Phys. Chem. Chem. Phys. 2016, 18 (30), 20091-20096.

42. Berger, O.; Gazit, E., Molecular self-assembly using peptide nucleic acids. Biopolymers 2017, $108(1)$

43. Sasselov, D. D.; Grotzinger, J. P.; Sutherland, J. D., The origin of life as a planetary phenomenon. Sci Adv 2020, 6 (6), eaax3419.

44. Smith, K. E.; House, C. H.; Arevalo, R. D., Jr.; Dworkin, J. P.; Callahan, M. P., Organometallic compounds as carriers of extraterrestrial cyanide in primitive meteorites. Nature Commun. 2019, 10 (1), 2777.

45. Grundke, C.; Opatz, T., Strecker reactions with hexacyanoferrates as non-toxic cyanide sources. Green. Chem. 2019, 21 (9), 2362-2366. 
46. Okamura, H.; Becker, S.; Tiede, N.; Wiedemann, S.; Feldmann, J.; Carell, T., A one-pot, water compatible synthesis of pyrimidine nucleobases under plausible prebiotic conditions. Chem Commun (Camb) 2019, 55 (13), 1939-1942.

47. Welcher, R. P.; Kaiser, D. W.; Wystrach, V. P., New Knowledge of Thioammeline. J. Am. Chem. Soc. 1959, 81 (21), 5663-5666.

48. Bann, B.; Miller, S. A., Melamine And Derivatives Of Melamine. Chem. Rev. 1958, 58 (1), 131-172.

49. Yu, S. S.; Solano, M. D.; Blanchard, M. K.; Soper-Hopper, M. T.; Krishnamurthy, R.; Fernandez, F. M.; Hud, N. V.; Schork, F. J.; Grover, M. A., Elongation of Model Prebiotic ProtoPeptides by Continuous Monomer Feeding. Macromolecules 2017, 50 (23), 9286-9294.

50. Pizzarello, S.; Shock, E., The Organic Composition of Carbonaceous Meteorites: The Evolutionary Story Ahead of Biochemistry. Cold Spring Harbor Perspect. Biol. 2010, 2 (3).

51. Martins, Z., The Nitrogen Heterocycle Content of Meteorites and Their Significance for the Origin of Life. Life (Basel) 2018, 8 (3).

52. Materese, C. K.; Nuevo, M.; Sandford, S. A., N- And O-Heterocycles Produced from the Irradiation of Benzene and Naphthalene in H2O/NH3-Containing Ices. The Astrophysical Journal 2015, $800(2)$.

53. Parker, D. S. N.; Kaiser, R. I.; Kostko, O.; Troy, T. P.; Ahmed, M.; Sun, B. J.; Chen, S. H.; Chang, A. H. H., On the formation of pyridine in the interstellar medium. Phys. Chem. Chem. Phys. 2015, 17 (47), 32000-32008.

54. Mittapalli, G. K.; Osornio, Y. M.; Guerrero, M. A.; Reddy, K. R.; Krishnamurthy, R.; Eschenmoser, A., Mapping the landscape of potentially primordial informational oligomers: 
oligodipeptides tagged with 2,4-disubstituted 5-aminopyrimidines as recognition elements. Angew. Chem., Int. Ed. Engl. 2007, 46 (14), 2478-2484.

55. Zhang, X. J.; Krishnamurthy, R., Mapping the landscape of potentially primordial informational oligomers: oligo-dipeptides tagged with Oootic acid derivatives as recognition elements. Angew. Chem., Int. Ed. Engl. 2009, 48 (43), 8124-8128.

56. Folsome, C. E.; Lawless, J. G.; Romiez, M.; Ponnaamperuma, C., Heterocyclic compounds recovered from carbonaceous chondrites. Geochim. Cosmochim. Acta 1973, 37 (3), 455-465.

57. Ervasti, H. K.; Jobst, K. J.; Burgers, P. C.; Ruttink, P. J. A.; Terlouw, J. K., The acrylonitrile dimer ion: A study of its dissociation via self-catalysis, self-protonation and cyclization into the pyrimidine radical cation. Int. J. Mass Spectrom. 2007, 262 (1-2), 88-100.

58. Rony, P. R., Polyfunctional catalysis. III. Tautomeric catalysis. J. Am. Chem. Soc. 1969, 91 (22), 6090-6096.

59. Cafferty, B. J.; Gallego, I.; Chen, M. C.; Farley, K. I.; Eritja, R.; Hud, N. V., Efficient selfassembly in water of long noncovalent polymers by nucleobase analogues. J. Am. Chem. Soc. 2013, 135 (7), 2447-2450.

60. Cafferty, B. J.; Avirah, R. R.; Schuster, G. B.; Hud, N. V., Ultra-sensitive pH control of supramolecular polymers and hydrogels: pK(a) matching of biomimetic monomers. Chem. Sci. 2014, 5 (12), 4681-4686.

61. Kroll, H., The Participation of Heavy Metal Ions in the Hydrolysis of Amino Acid Esters. J. Am. Chem. Soc. 1952, 74 (8), 2036-2039.

62. Van Nostrum, C. F.; Veldhuis, T. F. J.; Bos, G. W.; Hennink, W. E., Hydrolytic degradation of oligo(lactic acid): a kinetic and mechanistic study. Polymer 2004, 45, 6779-6787. 
63. Walker, S. I.; Grover, M. A.; Hud, N. V., Universal sequence replication, reversible polymerization and early functional biopolymers: A model for the initiation of prebiotic sequence evolution. PLOS ONE 2012, 7 (4), e34166.

64. Benner, S. A.; Bell, E. A.; Biondi, E.; Brasser, R.; Carell, T.; Kim, H. J.; Mojzsis, S. J.; Omran, A.; Pasek, M. A.; Trail, D., When Did Life Likely Emerge on Earth in an RNA-First Process? ChemSystemsChem 2020, 2 (2).

65. Cafferty, B. J.; Hud, N. V., Was a pyrimidine-pyrimidine base pair the ancestor of Watson-Crick base pairs? Insights from a systematic approach to the origin of RNA. Isr. J. Chem. 2015, 55 (8), 891-905.

\section{Acknowledgments}

The authors thank Martin C, Tyler Roche, and Prof. Charles Liotta for helpful discussions, and Gary Newnam and Leslie Gelbaum for technical assistance. This work was supported by the NSF and the NASA Astrobiology Program under the NSF Center for Chemical Evolution (CHE1504217).

\section{Author contributions}

N.V.H. and D.M.F. conceived the study. D.M.F., S.C.K., N.V.H., R.K., and G.B.S. designed the experiments. D.M.F., S.C.K., K.W.G., and I.M. performed the experiments. D.M.F. and S.C.K. analyzed the data. All authors discussed the results. D.M.F. and N.V.H. wrote the paper with input from R.K., G.B.S., S.C.K., K.W.G., and I.M. D.M.F. wrote the Supplementary Information.

\section{Competing financial interests}


bioRxiv preprint doi: https://doi.org/10.1101/2020.09.01.278838; this version posted September 4, 2020. The copyright holder for this preprint (which was not certified by peer review) is the author/funder. All rights reserved. No reuse allowed without permission.

The authors declare no competing financial interests. 